\title{
Consumo e digestibilidade em bovinos em pastejo durante o período das águas sob suplementação com fontes de compostos nitrogenados e de carboidratos ${ }^{1}$
}

\author{
Viviane Aparecida Carli Costa ${ }^{2}$, Edenio Detmann ${ }^{3}$, Mário Fonseca Paulino ${ }^{3}$, Sebastião de \\ Campos Valadares Filho ${ }^{3}$, Isabela Pena Carvalho de Carvalho ${ }^{4}$, Luana Pereira Monteiro ${ }^{5}$
}

1 Trabalho conduzido com apoio do CNPq, FAPEMIG (PPM) e INCT-Ciência Animal.

2 Laboratório de Zootecnia e Nutrição Animal, Universidade Estadual do Norte Fluminense, Campos dos Goytacazes-RJ.

${ }^{3}$ Departamento de Zootecnia, Universidade Federal de Viçosa, Viçosa-MG. Pesquisador do CNPq e do INCT - Ciência Animal.

${ }^{4}$ Programa de Pós-Graduação em Zootecnia, Universidade Estadual Paulista, Jaboticabal-SP.

5 Graduação em Zootecnia, Universidade Federal de Viçosa, Viçosa-MG.

RESUMO - Objetivou-se avaliar os efeitos de diferentes formas químicas de compostos nitrogenados (proteicos e nãoproteicos) e de carboidratos (amiláceos e fibra solúvel) sobre o consumo, a digestibilidade e a síntese ruminal de proteína microbiana em bovinos sob suplementação durante o período das águas. Foram utilizados cinco novilhos mestiços Holandês $\times$ Zebu, com peso vivo (PV) médio inicial de $211 \pm 35 \mathrm{~kg}$, fistulados no rúmen e abomaso. Os tratamentos foram: controle (somente pasto); e suplementos formulados à base de milho + farelo de soja; milho + ureia; polpa cítrica + farelo de soja; e polpa cítrica + ureia. Os suplementos foram balanceados para apresentar 30\% de proteína bruta (PB), com base na matéria seca (MS), e fornecidos na quantidade de $3 \mathrm{~g} / \mathrm{kg}$ PV. O experimento foi conduzido segundo delineamento em quadrado latino $5 \times 5$, em esquema fatorial $2 \times 2+1$, composto de duas fontes de compostos nitrogenados, duas fontes de carboidratos e tratamento controle. O consumo de pasto reduziu com o fornecimento de suplementos, com coeficiente médio de substituição de 2,11 g de MS de pasto/g de MS de suplemento. A suplementação não alterou os coeficientes de digestibilidade total e ruminação da MS nem o teor dietético de nutrientes digestíveis totais (NDT). Os animais sob suplementação apresentaram maiores coeficientes de digestibilidade total e ruminal da proteína bruta. A eficiência de síntese de proteína microbiana (EFSM), média de 123,1 g PB microbiana/kg de NDT, não foi alterada pela suplementação. Contudo, os animais sob suplementação com milho apresentaram maior EFSM em comparação aos animais sob suplementação com polpa cítrica (137,6 e 106,1 g PB microbiana/kg de NDT, respectivamente). A suplementação proteico-energética para bovinos mantidos em pastos tropicais durante o período das águas não causa benefícios nutricionais, o que reflete o alto coeficiente de substituição da forragem pelo suplemento.

Palavras-chave: amido, fibra solúvel, suplementação proteico-energética, ureia

\section{Intake and digestibility in cattle under grazing during rainy season and supplemented with different sources of nitrogenous compounds and carbohydrates}

\begin{abstract}
The objective of this work was to evaluate the effects of different chemical forms of nitrogenous compounds (protein and non-protein) and carbohydrates (starch and soluble fiber) on intake, digestibility, and ruminal synthesis of microbial protein in cattle supplemented during rainy season. It was used five crossbred Holstein $\times$ Zebu steers, with average initial body weight of $211 \pm 35 \mathrm{~kg}$ and fistulated in the rumen and abomasum. The treatments were: control (only pasture), and supplements based on corn + soybean meal; corn + urea, citrus pulp + soybean meal, and citrus pulp + urea. The supplements were balanced to present $30 \%$ of crude protein (CP), on dry matter (DM) basis, and provided at $3 \mathrm{~g} / \mathrm{kg} \mathrm{BW}$. The experiment was carried out according to a $5 \times 5$ Latin square design in a $2 \times 2+1$ factorial arrangement, composed of two sources of nitrogenous compounds, two sources of carbohydrates and a control treatment. Pasture intake was reduced when supplements were fed to animals, with average substitution coefficient of $2.11 \mathrm{~g}$ of DM of pasture/g of DM of supplement. Supplementation did not alter the total and ruminal digestibility coefficients of DM and the dietary content of total digestible nutrients (TDN) neither. Supplemented animals presented higher ruminal and total digestibility coefficients of CP than non-supplemented animals. The efficiency of microbial protein synthesis (EMPS), average of $123.1 \mathrm{~g}$ of microbial $\mathrm{CP} / \mathrm{kg}$, was not changed by supplementation. However, animals supplemented with corn presented higher EMPS in comparison to animals supplemented with citrus pulp (137.6 and $106.1 \mathrm{~g}$ microbial $\mathrm{CP} / \mathrm{kg}$ of $\mathrm{TDN}$, respectively). Protein-energy supplementation for cattle grazing in tropical pastures during rainy season does not cause nutritional benefits, which reflects the high coefficient of substitution of forage by the supplement.
\end{abstract}

Key Words: energy-protein supplementation, soluble fiber, starch, urea 


\section{Introdução}

A utilização do pasto pelos animais durante o período das águas em comparação ao período seco não pode ser vista como otimizada considerando apenas o maior desempenho animal (Detmann et al., 2010). Embora os pastos tropicais na época das águas não sejam considerados deficientes em proteína, elevada proporção dos compostos nitrogenados totais do pasto pode ser encontrada na forma insolúvel em detergente neutro (Paulino et al., 2008), considerada de lenta e incompleta degradação, podendo implicar carência de compostos nitrogenados aos microrganismos ruminais.

Em algumas argumentações teóricas relacionadas à nutrição de bovinos em pastejo, afirma-se que a suplementação com compostos nitrogenados prontamente degradáveis no rúmen durante o período de franco crescimento forrageiro não seria capaz de incrementar, ou seria deletéria à produção animal, notadamente em função de ampliação do metabolismo hepático de nitrogênio e do incremento calórico, com redução do consumo voluntário de forragem (Poppi \& McLennan, 1995; Paulino et al., 2008). Contudo, resultados obtidos em condições tropicais têm evidenciado que a suplementação com fontes proteicas degradáveis no rúmen (Paulino et al., 2006; Figueiredo et al., 2008), incluindo o uso de ureia como principal composto nitrogenado dos suplementos, tem incrementado o desempenho animal durante o período das águas (Detmann et al., 2010).

Por outro lado, a inclusão de carboidratos não-fibrosos (CNF) em suplementos ofertados a bovinos durante o período das águas tem sido sugerida no sentido de permitir melhor assimilação dos compostos nitrogenados de rápida degradação no ambiente ruminal (Detmann et al., 2005a).

No entanto, de forma recente, tem-se estabelecido que a forma como os suplementos afetam o ambiente ruminal pode variar em função da origem química dos carboidratos presentes no suplemento (Costa et al., 2009).

Contudo, são escassos os estudos nos quais se investigam a interação entre diferentes formas químicas de compostos nitrogenados e de carboidratos sobre a utilização de pastos de gramíneas tropicais de alta qualidade, como aqueles observados durante o período das águas.

Assim, objetivou-se avaliar os efeitos de diferentes formas químicas de compostos nitrogenados (proteicos e não-proteicos) e de carboidratos (amiláceos e fibra solúvel) em suplementos para bovinos em pastejo de capimbraquiária (Brachiaria decumbens Stapf.) durante o período das águas sobre o consumo, a digestibilidade e a síntese de proteína microbiana.

\section{Material e Métodos}

O experimento foi conduzido no Setor de Bovinocultura de Corte do Departamento de Zootecnia da Universidade Federal de Viçosa, Minas Gerais, entre dezembro de 2006 e março de 2007.

Foram utilizados cinco novilhos mestiços Holandês $\times$ Zebu, castrados, com peso vivo (PV) inicial de $211 \pm 35 \mathrm{~kg}$ e fistulados no rúmen e no abomaso.

A área experimental foi composta por cinco piquetes de capim-braquiária, com 0,34 ha cada, contendo bebedouro e comedouro coberto, sendo cada animal manejado em um piquete. Paralelamente aos piquetes, situava-se o curral de manejo, no qual foram realizadas as coletas nos animais (fezes, conteúdo ruminal, etc). Todos os animais tiveram acesso irrestrito a água e mistura mineral completa ( $9 \%$ de fósforo).

Foram avaliados os seguintes tratamentos: controle (sem suplementação); milho + farelo de soja; milho + ureia; polpa cítrica + farelo de soja; e polpa cítrica + ureia (Tabela 1 ). Os suplementos foram balanceados para apresentar $30 \%$ de proteína bruta (PB), com base na matéria seca (MS), e fornecidos diariamente às $12 \mathrm{~h}$ na quantidade de $3 \mathrm{~g} / \mathrm{kg} \mathrm{PV}$. Os níveis de suplementação e de PB nos suplementos foram definidos de forma a fornecer aproximadamente $30 \%$ das exigências de PB de um novilho zebuíno, castrado, com $250 \mathrm{~kg}$ de PV e ganho médio diário de $1 \mathrm{~kg}$, segundo recomendações de Valadares Filho et al. (2006). As fontes alimentares utilizadas na formulação dos suplementos foram escolhidas de forma a contrastarem-se carboidratos de origem amilácea (milho grão) e fibrosa solúvel (polpa cítrica) e fontes de compostos nitrogenados de origem proteica (farelo de soja) e não-proteica (ureia:sulfato de amônio, 9:1).

O experimento foi conduzido segundo delineamento em quadrado latino $5 \times 5$, em cinco períodos experimentais com 15 dias cada, sendo os cinco primeiros dias destinados à adaptação dos animais à suplementação.

No primeiro dia de cada período experimental, quantificou-se a massa de forragem disponível em cada piquete por intermédio do corte rente ao solo de cinco áreas

Tabela 1 - Composição dos suplementos (\%) com base na matéria natural

\begin{tabular}{|c|c|c|c|c|}
\hline \multirow[b]{2}{*}{ Item } & \multirow[b]{2}{*}{ MFS } & \multicolumn{2}{|c|}{ Suplemento $^{1}$} & \multirow[b]{2}{*}{ PU } \\
\hline & & MU & PFS & \\
\hline Milho grão & 50,4 & 91,2 & - & - \\
\hline Polpa cítrica & - & - & 48,3 & 90,7 \\
\hline Farelo de soja & 47,6 & - & 49,7 & - \\
\hline Ureia:sulfato de amônio & - & 6,8 & - & 7,3 \\
\hline Mistura mineral & 2,0 & 2,0 & 2,0 & 2,0 \\
\hline
\end{tabular}

R. Bras. Zootec., v.40, n.8, p.1788-1798, 2011 
delimitadas por um quadrado de dimensões $0,5 \times 0,5 \mathrm{~m}$, selecionadas ao acaso em cada piquete. As amostras, depois de pesadas, foram avaliadas quanto ao teor de MS (Silva \& Queiroz, 2002). A disponibilidade média de forragem foi de 10,3; 11,6; 10,1; 10,7 e 10,5 t MS/ha para os períodos experimentais em seqüência.

A avaliação da forragem ingerida pelos animais foi realizada no primeiro, quinto e décimo dias de cada período experimental por intermédio de simulação manual de pastejo. As amostras foram secas sob ventilação forçada $\left(60^{\circ} \mathrm{C}\right)$, processadas em moinho de facas ( 1 e $2 \mathrm{~mm}$ ) e posteriormente compostas, como base no peso seco ao ar, por piquete e período experimental.

Para estimação da excreção fecal utilizou-se dióxido de titânio como indicador externo, o qual foi fornecido às $12 \mathrm{~h}$ (20 g/dia), via fístula ruminal, entre o primeiro e oitavo dias de cada período experimental. As coletas fecais foram realizadas de acordo com o cronograma: 6 - dia -8 h e $14 \mathrm{~h}$; 70 dia -10 h e 16 h e 8 o dia -12 h e 18 h. Simultaneamente à coleta fecal foram tomadas amostras de digesta abomasal. As amostras de fezes e digesta abomasal foram secas sob ventilação forçada $\left(60^{\circ} \mathrm{C}\right)$ e processadas em moinho de facas (1 e $2 \mathrm{~mm}$ ). Posteriormente, elaboraram-se amostras compostas, com base no peso seco ao ar, por animal e período experimental.

Para avaliação do pH e da concentração de nitrogênio amoniacal ruminal (NAR) foram realizadas, no nono dia do período experimental, coletas de líquido ruminal às $6 \mathrm{~h}, 12 \mathrm{~h}$, $18 \mathrm{~h}$ e $24 \mathrm{~h}$. As amostras foram coletadas manualmente na interface líquido:sólido do ambiente ruminal, filtradas por camada tripla de gaze e submetidas à avaliação do $\mathrm{pH}$ por intermédio de potenciômetro digital. Em seguida, separou-se alíquota de $40 \mathrm{~mL}$, a qual foi fixada com $1 \mathrm{~mL} \mathrm{de} \mathrm{H}_{2} \mathrm{SO}_{4}(1: 1)$ e congelada $\left(-20^{\circ} \mathrm{C}\right)$.

No nono dia de cada período experimental foi realizada coleta de conteúdo ruminal para isolamento de microrganismos ruminais. As amostras foram tomadas imediatamente antes e seis horas após o fornecimento do suplemento (12 h e $18 \mathrm{~h}$ ), conforme Cecava et al. (1990).

Do $10^{\circ}$ ao $15^{\circ}$ dia do período experimental, foi realizado procedimento para avaliação da cinética de trânsito de partículas fibrosas, o qual foi baseado no fornecimento de indicador externo, em procedimento de dose pulso, empregando-se como indicador o cromo mordente à fibra, produzido conforme descrição de Udén et al. (1980). A base fibrosa para produção do indicador foi retirada de amostras de pasto obtidas por simulação manual de pastejo no primeiro dia de cada período experimental. Para simulação da atividade inicial de mastigação pelo animal, as amostras foram submetidas a um processo de moagem tripla em moinho de facas, sem peneira (Detmann et al., 2005b).

Foram fornecidos, para cada animal, $100 \mathrm{~g}$ de fibra mordente, diretamente no rúmen, às 8 h00 do décimo dia, sendo as amostras fecais obtidas em: 0, 3, 6, 9, 12, 18, 24, 30, 36, 48, 60, 72, 84, 96, 108 e 120 horas após o fornecimento do indicador. As amostras foram secas sob ventilação forçada $\left(60^{\circ} \mathrm{C}\right)$ e processadas em moinho de facas $(1 \mathrm{~mm})$.

No $15^{\circ}$ dia foram realizadas coletas de urina, na forma de amostra spot, em micção espontânea dos animais, aproximadamente 2 horas antes (10 h) e 4 horas após (16 h) o fornecimento dos suplementos. As amostras foram filtradas em gaze e uma alíquota de $10 \mathrm{~mL}$ foi separada, diluída com $40 \mathrm{~mL}$ de ácido sulfúrico $(0,036 \mathrm{~N})$ e congelada $\left(-20^{\circ} \mathrm{C}\right)$. Simultaneamente à amostragem urinária foram coletadas amostras de sangue diretamente da veia jugular utilizando-se tubos com vácuo e gel acelerador de coagulação (BD Vacuntainer ${ }^{\circledR}$ SST II Advance). O sangue foi imediatamente centrifugado a $2700 \mathrm{x}$ g por 15 minutos para obtenção do soro e armazenado $\left(-20^{\circ} \mathrm{C}\right)$.

As amostras de pasto obtidas via simulação manual, suplementos, digesta abomasal e fezes, processadas em peneira de $1 \mathrm{~mm}$, foram avaliadas quanto aos teores de MS, matéria orgânica (MO), $\mathrm{PB}$, extrato etéreo (EE), fibra em detergente ácido (FDA) e lignina $\left(\mathrm{H}_{2} \mathrm{SO}_{4} 72 \% \mathrm{p} / \mathrm{p}\right)$, segundo técnicas descritas por Silva \& Queiroz (2002). Os teores de fibra em detergente neutro (FDN) foram estimados segundo recomendações de Mertens (2002). As correções no tocante aos teores de cinzas e proteína contidos na FDN e na FDA foram conduzidas conforme recomendações de Mertens (2002) e Licitra et al. (1996), respectivamente (Tabela 2).

Os teores de CNF foram estimados por (Detmann \& Valadares Filho, 2010):

$C N F=M O-[E E+F D N c p+(P B-P B u+U)]$

em que: $\mathrm{CNF}=$ teor de carboidratos não-fibrosos (\%); $\mathrm{MO}=$ teor de matéria orgânica (\%); EE = teor de extrato etéreo (\%); FDNcp = teor de fibra em detergente neutro corrigida para cinzas e proteína (\%); PB = teor de proteína bruta (\%); $\mathrm{PBu}=$ teor de proteína bruta oriunda da ureia (\%); $\mathrm{U}=$ teor de ureia (\%).

As amostras fecais referentes à estimação da excreção fecal foram avaliadas por colorimetria quanto ao teor de dióxido de titânio (Titgemeyer et al., 2001). A excreção fecal foi estimada por intermédio da relação entre dose diária e concentração fecal do indicador.

As estimativas de consumo voluntário e de fluxo abomasal foram obtidas utilizando-se a FDN indigestível (FDNi) como indicador interno, quantificadas por procedimento de incubação in situ por 240 horas 
Tabela 2 - Composição química do pasto e dos suplementos

\begin{tabular}{|c|c|c|c|c|c|}
\hline \multirow[t]{2}{*}{ Item } & \multicolumn{4}{|c|}{ Suplemento } & \multirow[b]{2}{*}{ Pasto $^{1}$} \\
\hline & MFS & MU & PFS & $\mathrm{PU}$ & \\
\hline Matéria seca (\% matéria natural) & 93,81 & 94,28 & 92,45 & 91,61 & $24,51 \pm 2,47$ \\
\hline Matéria orgânica (\% da MS) & 94,97 & 97,50 & 92,81 & 94,00 & $90,71 \pm 0,15$ \\
\hline Proteína bruta (\% da MS) & 29,52 & 29,94 & 31,54 & 28,29 & $9,93 \pm 0,29$ \\
\hline Extrato etéreo (\% da MS) & 1,74 & 2,18 & 2,27 & 2,77 & $1,15 \pm 0,06$ \\
\hline Fibra em detergente neutro (\% da MS) & 15,94 & 14,94 & 18,73 & 21,10 & $71,65 \pm 0,59$ \\
\hline FDNcp (\% da MS) & 13,26 & 10,68 & 13,31 & 17,38 & $64,58 \pm 0,46$ \\
\hline PIDN (\% da MS) & 7,01 & 13,26 & 18,56 & 15,09 & $46,56 \pm 2,49$ \\
\hline Carboidratos não-fibrosos (\% da MS) & 50,41 & 66,47 & 45,69 & 56,46 & $15,05 \pm 0,35$ \\
\hline Fibra em detergente ácido (\% da MS) & - & - & - & - & $41,15 \pm 0,90$ \\
\hline FDAcp (\% da MS) & - & - & - & - & $38,87 \pm 0,99$ \\
\hline PIDA (\%PB) & - & - & - & - & $25,84 \pm 1,83$ \\
\hline Lignina (\% da MS) & - & - & - & - & $4,49 \pm 0,23$ \\
\hline FDNi (\% da MS) & 1,96 & 1,46 & 2,57 & 3,71 & $17,28 \pm 0,54$ \\
\hline
\end{tabular}

MFS = milho + farelo de soja; MU = milho + ureia; PFS = polpa cítrica + farelo de soja; PU = polpa cítrica + ureia; FDNcp = fibra em detergente neutro corrigida para cinzas e proteína; FDAcp = fibra em detergente ácido corrigida para cinzas e proteína; FDNi = fibra em detergente neutro indigestível.

${ }^{1}$ Média \pm erro-padrão da média (amostras obtidas por simulação manual de pastejo).

utilizando-se as alíquotas processadas em peneira de malha 2 mm, segundo recomendações de Casali et al. (2008).

A concentração de nitrogênio amoniacal ruminal (NAR) foi quantificada de acordo com a técnica colorimétrica proposta por Chaney \& Marbach (1962). As concentrações obtidas nos diferentes tempos de amostragem foram combinadas por animal e período experimental, produzindo-se a média diária de concentração de NAR. Combinação similar foi conduzida sobre os valores de $\mathrm{pH}$ ruminal.

As amostras de microrganismos ruminais foram avaliadas quanto aos teores de PB (Silva \& Queiroz, 2002) e bases púricas (Ushida et al., 1985). A produção ruminal de compostos nitrogenados microbianos foi quantificada por intermédio do produto entre concentração na digesta abomasal e fluxo diário de MS abomasal. As bases púricas foram utilizadas como indicadores para avaliação da concentração microbiana na digesta abomasal, tomado-se como base a relação $\mathrm{N}_{\mathrm{RNA}}: \mathrm{N}_{\text {total }}$ nos microrganismos ruminais.

As amostras de soro, após descongelamento, foram analisadas quanto aos teores de ureia, segundo método enzimático-colorimétrico (Bioclin ${ }^{\circledR} \mathrm{K} 047$ ).

As amostras de urina, depois de descongeladas, foram compostas por animal e período experimental e analisadas quanto aos teores de ureia, como descrito anteriormente, creatinina, segundo o método de Jaffé modificado (Bioclin ${ }^{\circledR}$ K016-1), e nitrogênio total, segundo método de Kjeldahl (Silva \& Queiroz, 2002).

O volume urinário foi estimado por intermédio da relação entre concentração de creatinina na urina e sua excreção por unidade de PV, segundo equação descrita por Chizzotti et al. (2006):

$E C=32,27-0,01093 \times P V$ em que: EC = excreção diária de creatinina (mg/kg PV); e $\mathrm{PV}=$ peso vivo $(\mathrm{kg})$.

As amostras de fezes relativas à quantificação da cinética de trânsito foram analisadas quanto aos teores de MS (Silva \& Queiroz, 2002) e cromo (Williams et al., 1962).

Os parâmetros da cinética de trânsito foram estimados por intermédio do ajustamento à curva de excreção fecal do indicador de modelo gama-2 tempo-dependente (Ellis et al., 1994):

$C_{t}=Z \times(t-\tau) \times \gamma \times \exp [-\gamma \times(t-\tau)]$

em que: $\mathrm{C}_{\mathrm{t}}=$ concentração fecal do indicador no tempo " $\mathrm{t}$ " $(\mathrm{ppm}) ; \mathrm{t}=$ tempo após o fornecimento do indicador $(\mathrm{h})$; $\gamma=$ parâmetro taxa tempo-dependente relativo ao fluxo ruminal de partículas fibrosas $\left(\mathrm{h}^{-1}\right) ; \mathrm{Z}=$ parâmetro sem interpretação biológica direta $(\mathrm{ppm} \times \mathrm{h})$; e $\tau=$ tempo decorrido entre a aplicação e o aparecimento do indicador nas fezes (h).

$\mathrm{O}$ experimento foi analisado em esquema fatorial $2 \times 2+1$ (duas fontes de compostos nitrogenados, duas fontes de carboidratos, adicionando-se tratamento controle). Para os ajustamentos não-lineares relativos à equação (3) utilizou-se o algoritmo iterativo de Gauss-Newton. Neste caso, a comparação entre tratamentos foi realizada por intermédio do teste de identidade de modelos não-lineares proposto por Regazzi (2003). Todos os procedimentos estatísticos foram conduzidos utilizando-se o programa SAS (Statistical Analysis System, versão 9.1) e adotando-se $\alpha=0,10$.

Um dos animais apresentou problemas não relacionados aos tratamentos experimentais durante a segunda metade do quinto período experimental, havendo assim a perda de informações no tocante às variáveis associadas ao metabolismo dos compostos nitrogenados e taxa de passagem. 


\section{Resultados e Discussão}

Para nenhuma das variáveis avaliadas neste estudo foi verificada interação entre as fontes de carboidratos e de compostos nitrogenados $(\mathrm{P}>0,10)$. Assim, os efeitos destas variáveis independentes foram apresentados e discutidos isoladamente.

Não foram observados efeitos das fontes de carboidratos e compostos nitrogenados sobre as estimativas de consumo voluntário ( $\mathrm{P}>0,10)$, com exceção do consumo de FDNi, que foi inferior $(\mathrm{P}<0,10)$ com a suplementação com polpa cítrica em comparação ao milho (kg/dia e g/kg PV) e inferior $(\mathrm{P}<0,10)$ com a suplementação com ureia em relação ao farelo de soja (g/kg PV) (Tabela 3).

A suplementação não afetou $(\mathrm{P}>0,10)$ o consumo de MS e MO; contudo, observou-se redução $(\mathrm{P}<0,10)$ dos consumos de MS e MO de pasto com o fornecimento de suplemento em ambas as unidades avaliadas (Tabela 3). O efeito substitutivo médio para o consumo de MS de pasto foi 2,11 g MS de pasto/g MS de suplemento.

Como reflexo da redução no consumo de pasto, a suplementação implicou redução $(P<0,10)$ nos consumos de EE, FDNcp, FDNcp de pasto e FDNi (Tabela 3). Por outro lado, não foram verificados efeitos relativos à suplementação $(\mathrm{P}>0,10)$ sobre os consumos de $\mathrm{PB}, \mathrm{CNF}$, MS digerida, FDN digerida e de NDT (Tabela 3).

A suplementação reduziu $(\mathrm{P}<0,10)$ o consumo de $\mathrm{PB}$ de pasto. O coeficiente médio de substituição foi de $0,88 \mathrm{~g}$ de PB de pasto/g de PB oriunda dos suplementos, o que levou a valores similares de consumo de PB total entre animais sob suplementação e sem suplementação (Tabela 3).

A alteração da fonte de compostos nitrogenados não afetou $(\mathrm{P}>0,10)$ as estimativas dos coeficientes de digestibilidade total, com exceção dos CNF que foram mais digeridos $(\mathrm{P}<0,10)$ com a utilização de ureia em comparação ao farelo de soja. Os teores de NDT nas dietas foram similares $(\mathrm{P}>0,10)$ para ambas as fontes de compostos nitrogenados (Tabela 4).

Efeitos das fontes de carboidratos foram verificados sobre os coeficientes de digestibilidade total do EE e dos CNF, os quais foram superiores $(P<0,10)$ com a utilização de polpa cítrica em relação ao milho grão. Esta elevação implicou maiores estimativas $(\mathrm{P}<0,10)$ do coeficiente de digestibilidade total da MO e do teor de NDT na dieta

Tabela 3 - Médias, coeficientes de variação (CV) e níveis descritos de probabilidades para contrastes (valor-P) para o consumo voluntário em bovinos em pastejo recebendo fontes de compostos nitrogenados e carboidratos

\begin{tabular}{|c|c|c|c|c|c|c|c|c|c|c|}
\hline \multirow[t]{2}{*}{ Item } & \multicolumn{5}{|c|}{ Tratamento $^{1}$} & \multirow[t]{2}{*}{ CV (\%) } & \multicolumn{4}{|c|}{ Valor-P ${ }^{2}$} \\
\hline & $\mathrm{C}$ & MFS & MU & PFS & $\mathrm{PU}$ & & $\mathrm{C} \times \mathrm{S}$ & $\mathrm{CH}$ & $\mathrm{CN}$ & INT \\
\hline & & & & & & kg/dia & & & & \\
\hline Matéria seca & 5,33 & 4,89 & 4,58 & 4,56 & 4,53 & 19,9 & 0,173 & 0,673 & 0,694 & 0,750 \\
\hline Matéria seca do pasto & 5,33 & 4,27 & 3,94 & 3,93 & 3,91 & 22,1 & 0,017 & 0,666 & 0,681 & 0,724 \\
\hline$\Delta \mathrm{MSP}^{3}$ & - & $-1,73$ & $-2,19$ & $-2,22$ & $-2,29$ & - & - & - & - & - \\
\hline Matéria orgânica & 4,81 & 4,47 & 4,20 & 4,16 & 4,13 & 19,7 & 0,212 & 0,633 & 0,706 & 0,766 \\
\hline Matéria orgânica do pasto & 4,81 & 3,88 & 3,58 & 3,58 & 3,54 & 21,9 & 0,019 & 0,658 & 0,671 & 0,729 \\
\hline Proteína bruta & 0,56 & 0,59 & 0,59 & 0,57 & 0,56 & 20,9 & 0,720 & 0,661 & 0,875 & 0,945 \\
\hline Proteína bruta do pasto & 0,56 & 0,41 & 0,40 & 0,37 & 0,38 & 28,8 & 0,019 & 0,642 & 0,978 & 0,832 \\
\hline$\Delta \mathrm{PBP}^{3}$ & - & $-0,80$ & $-0,83$ & $-0,91$ & $-0,98$ & - & - & - & - & - \\
\hline Extrato etéreo & 0,07 & 0,05 & 0,05 & 0,06 & 0,07 & 20,9 & 0,066 & 0,135 & 0,220 & 0,418 \\
\hline FDNcp & 3,30 & 2,91 & 2,61 & 2,67 & 2,61 & 21,5 & 0,073 & 0,663 & 0,513 & 0,663 \\
\hline FDNcpP & 3,30 & 2,84 & 2,53 & 2,57 & 2,56 & 22,0 & 0,048 & 0,659 & 0,561 & 0,599 \\
\hline$\Delta \mathrm{FDNcpP}^{3}$ & - & $-0,74$ & $-1,21$ & $-1,15$ & $-1,19$ & - & - & - & - & - \\
\hline Carboidratos não-fibrosos & 0,88 & 0,90 & 1,03 & 0,88 & 0,91 & 17,7 & 0,586 & 0,324 & 0,284 & 0,481 \\
\hline Matéria seca digerida & 3,00 & 2,82 & 2,61 & 2,83 & 2,86 & 30,3 & 0,610 & 0,731 & 0,813 & 0,763 \\
\hline FDNcp digerida & 2,09 & 1,82 & 1,57 & 1,77 & 1,76 & 30,3 & 0,213 & 0,780 & 0,604 & 0,616 \\
\hline Nutrientes digestíveis totais & 3,17 & 2,94 & 2,85 & 2,93 & 3,02 & 25,8 & 0,679 & 0,663 & 0,990 & 0,793 \\
\hline \multirow[t]{2}{*}{ Fibra em detergente neutro indigestível } & 0,91 & 0,83 & 0,74 & 0,66 & 0,61 & 14,9 & 0,004 & 0,012 & 0,157 & 0,700 \\
\hline & & \multicolumn{9}{|c|}{ g/kg de peso vivo } \\
\hline Matéria seca & 25,7 & 23,7 & 21,7 & 21,9 & 21,7 & 17,3 & 0,113 & 0,625 & 0,552 & 0,635 \\
\hline Matéria seca do pasto & 25,7 & 20,7 & 18,7 & 18,9 & 18,8 & 19,2 & 0,007 & 0,623 & 0,557 & 0,606 \\
\hline Matéria orgânica & 23,2 & 21,7 & 20,0 & 20,0 & 19,8 & 17,2 & 0,144 & 0,579 & 0,561 & 0,655 \\
\hline Matéria orgânica do pasto & 23,2 & 18,8 & 17,0 & 17,2 & 17,0 & 19,1 & 0,008 & 0,613 & 0,545 & 0,617 \\
\hline FDNcp & 15,9 & 14,2 & 12,4 & 12,8 & 12,5 & 19,1 & 0,043 & 0,599 & 0,395 & 0,532 \\
\hline FDNcpP & 15,9 & 13,8 & 12,0 & 12,3 & 12,3 & 19,5 & 0,026 & 0,595 & 0,440 & 0,472 \\
\hline Fibra em detergente neutro indigestível & 4,4 & 4,1 & 3,5 & 3,2 & 2,9 & 12,1 & 0,001 & 0,003 & 0,055 & 0,479 \\
\hline
\end{tabular}

${ }^{1} \mathrm{C}=$ controle; MFS = milho + farelo de soja; MU = milho + ureia; PFS = polpa cítrica + farelo de soja; PU = polpa cítrica + ureia.

${ }^{2} \mathrm{C} \times \mathrm{S}=$ controle versus suplementos; $\mathrm{CH}=$ contraste entre as fontes de carboidratos; $\mathrm{CN}=$ contraste entre fontes de compostos nitrogenados; INT = interação entre fontes de carboidratos e de compostos nitrogenados.

${ }^{3} \Delta \mathrm{MSP}=$ variação sobre o consumo de MS de pasto em função do consumo de suplementos (g/g); $\Delta$ FDNcpP = variação sobre o consumo de FDNcp de pasto em função do consumo de suplementos (g/g); $\triangle \mathrm{PBP}=$ variação sobre o consumo de PB de pasto em função do consumo de PB dos suplementos (g/g). 
para os animais sob suplementação com polpa cítrica comparativamente ao milho (Tabela 4).

A suplementação não alterou $(\mathrm{P}<0,10)$ os coeficientes de digestibilidade total da MS, MO, EE, FDNcp e o teor dietético de NDT. Os animais sob suplementação apresentaram maiores $(\mathrm{P}<0,10)$ coeficientes de digestibilidade total da PB e dos CNF em comparação aos animais sem suplementação (Tabela 4).

Não foram verificados efeitos $(\mathrm{P}>0,10)$ das fontes de compostos nitrogenados sobre os coeficientes de digestibilidade ruminal. No tocante às fontes de carboidratos, verificaram-se maiores $(\mathrm{P}<0,10)$ coeficientes de digestibilidade ruminal do EE com o uso de polpa cítrica em relação ao milho grão. Os demais componentes não apresentaram $(\mathrm{P}>0,10)$ efeitos relativos às fontes de carboidratos (Tabela 4).

A suplementação não afetou $(\mathrm{P}>0,10)$ os coeficientes de digestibilidade ruminal da MS, MO, EE, FDNcp e CNF. Contudo, o fornecimento de suplementos elevou $(\mathrm{P}<0,10)$ o coeficiente de digestibilidade ruminal da PB. Em avaliação adicional, verificou-se que a não suplementação acarretou coeficiente de digestibilidade ruminal da $\mathrm{PB}$ negativo $(\mathrm{P}<0,10)$, ao passo que o fornecimento de suplementos tornou as estimativas deste parâmetro similares a zero $(\mathrm{P}>0,10)$ (Tabela 4).
Nenhum efeito $(\mathrm{P}>0,10)$ foi verificado sobre os coeficientes de digestibilidade intestinal (Tabela 4). Também não houve efeito $(\mathrm{P}>0,10)$ sobre as estimativas de $\mathrm{pH}$ ruminal e concentração de NAR, cujos valores médios foram de 6,42 e 6,85 mg/dL, respectivamente. Embora sem diferenças significativas $(P>0,10)$ as concentrações médias de NAR para os animais sob suplementação foram, em média, 2,02 mg/dL superiores em comparação aos animais sem suplementação (7,25 e 5,23 mg/dL, respectivamente) (Tabela 5).

O consumo de nitrogênio e a excreção urinária de nitrogênio não foram afetados por nenhum dos fatores avaliados $(\mathrm{P}>0,10)$. A excreção fecal de nitrogênio não foi afetada pela suplementação $(\mathrm{P}>0,10)$. Comparativamente, os animais sob suplementação com milho grão excretaram mais nitrogênio $(\mathrm{P}<0,10)$ nas fezes em comparação àqueles que receberam polpa cítrica, sem, contudo, causar alterações $(\mathrm{P}>0,10)$ sobre o balanço de compostos nitrogenados, que foi, em média, de 5,63 g de nitrogênio/dia (Tabela 5).

Nenhum efeito foi observado $(\mathrm{P}>0,10)$ sobre a excreção urinária de nitrogênio ureico, a concentração sérica de nitrogênio ureico (NUS) e sobre o fluxo abomasal de nitrogênio microbiano (NMIC), cujos valores médios foram de 36,88 g/dia, 15,09 mg/dL e 42,89 g/dia, respectivamente.

Tabela 4 - Médias, coeficientes de variação (CV) e níveis descritivos de probabilidade para contrastes (Valor-P) para os coeficientes de digestibilidade ruminal, intestinal e total e teor dietético de nutrientes digestíveis totais em bovinos em pastejo recebendo fontes de compostos nitrogenados e carboidratos

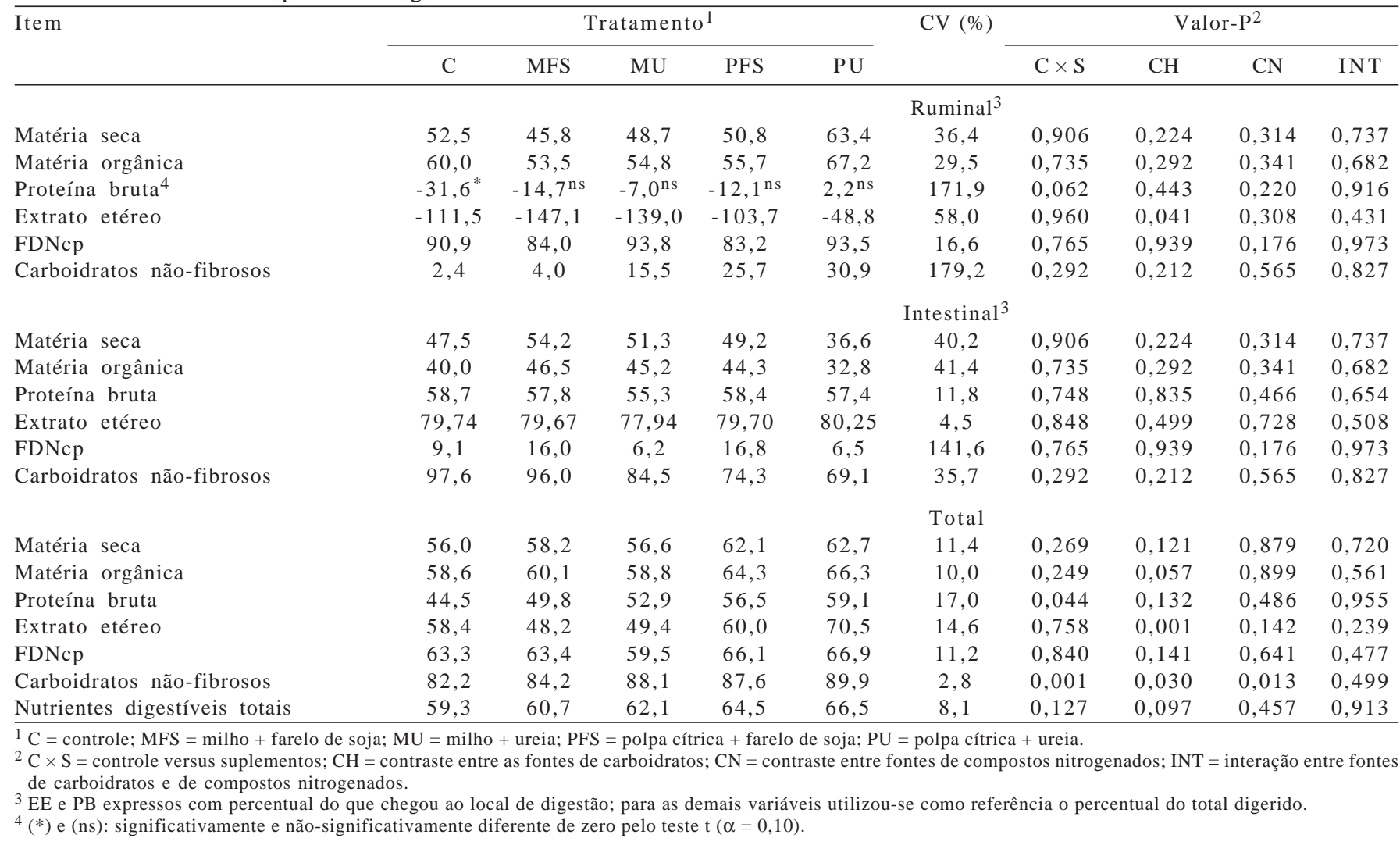


Tabela 5 - Médias de mínimos quadrados, coeficientes de variação (CV) e níveis descritivos de probabilidade para contrastes para o pH ruminal e características de utilização dos compostos nitrogenados em bovinos em pastejo recebendo fontes de compostos nitrogenados e carboidratos

\begin{tabular}{|c|c|c|c|c|c|c|c|c|c|c|}
\hline \multirow[t]{2}{*}{ Item } & \multicolumn{5}{|c|}{ Tratamento $^{1}$} & \multirow[t]{2}{*}{ CV(\%) } & \multicolumn{4}{|c|}{ Valor- $\mathrm{P}^{2}$} \\
\hline & $\mathrm{C}$ & MFS & MU & PFS & PU & & $\mathrm{C} \times \mathrm{S}$ & $\mathrm{CH}$ & $\mathrm{CN}$ & INT \\
\hline $\mathrm{pH}$ & 6,45 & 6,35 & 6,39 & 6,42 & 6,47 & 4,6 & 0,818 & 0,607 & 0,756 & 0,980 \\
\hline Consumo de nitrogênio (g/dia) & 88,87 & 94,70 & 93,93 & 91,45 & 94,27 & 21,0 & 0,639 & 0,876 & 0,913 & 0,847 \\
\hline Excreção fecal de nitrogênio (g/dia) & 46,92 & 46,66 & 44,24 & 40,23 & 39,12 & 14,3 & 0,193 & 0,074 & 0,558 & 0,826 \\
\hline Excreção urinária de nitrogênio (g/dia) & 39,88 & 40,82 & 43,14 & 46,11 & 47,93 & 15,2 & 0,183 & 0,126 & 0,513 & 0,942 \\
\hline Balanço aparente de nitrogênio (g/dia) & 2,07 & 7,18 & 6,55 & 5,12 & 7,21 & 223,5 & 0,562 & 0,921 & 0,918 & 0,848 \\
\hline N-ureico no soro $(\mathrm{mg} / \mathrm{dL})$ & 14,25 & 14,60 & 16,79 & 14,40 & 15,42 & 19,6 & 0,491 & 0,582 & 0,270 & 0,680 \\
\hline NMIC (g/dia) & 55,60 & 60,77 & 50,85 & 45,43 & 47,54 & 27,3 & 0,496 & 0,143 & 0,459 & 0,492 \\
\hline NMICR & 0,498 & 0,492 & 0,507 & 0,450 & 0,536 & 13,9 & 0,812 & 0,559 & 0,269 & 0,514 \\
\hline EFIM & 128,4 & 147,7 & 127,4 & 110,6 & 101,5 & 32,8 & 0,643 & 0,073 & 0,294 & 0,968 \\
\hline PDI/NDT (g/kg) & 152,2 & 163,4 & 141,6 & 153,9 & 107,3 & 36,3 & 0,695 & 0,419 & 0,218 & 0,635 \\
\hline NBAC (\% da MS) & 7,24 & 7,11 & 6,59 & 6,51 & 7,16 & 10,6 & 0,216 & 0,584 & 0,746 & 0,266 \\
\hline $\mathrm{N}_{\mathrm{RNA}}: \mathrm{NT}$ & 0,203 & 0,188 & 0,212 & 0,205 & 0,209 & 10,4 & 0,894 & 0,391 & 0,125 & 0,478 \\
\hline
\end{tabular}

${ }^{1} \mathrm{C}=$ controle; MFS = milho + farelo de soja; $\mathrm{MU}$ = milho + ureia; PFS = polpa cítrica + farelo de soja; PU = polpa cítrica + ureia.

${ }^{2} \mathrm{C} \times \mathrm{S}=$ controle versus suplementos; $\mathrm{CH}=$ contraste entre as fontes de carboidratos; $\mathrm{CN}=$ contraste entre fontes de compostos nitrogenados; INT = interação entre fontes de compostos nitrogenados e de carboidratos.

EUNU = excreção urinária de nitrogênio ureico; NMIC = fluxo intestinal de nitrogênio microbiano; NMIC relativo (NMICR - g NMIC/g nitrogênio ingerido); EFIM = eficiência de síntese microbiana (g PB microbiana/kg de NDT); PDI/NDT = relação entre proteína digerida no intestino e consumo de NDT; NBAC = concentração de nitrogênio nos microrganismos ruminais; e relação nitrogênio purina: nitrogênio total nos microrganismos ruminais ( $\mathrm{N}_{\mathrm{RNA}}$ :NT).

O NMIC representou, como média geral para todos os tratamentos, $49,7 \%$ do nitrogênio total consumido pelos animais (Tabela 5).

A eficiência de síntese de proteína microbiana (EFIM) não foi alterada $(\mathrm{P}>0,10)$ quando comparados animais sob suplementação e sem suplementação, com média global de 123,1 g PB microbiana/kg de NDT. Contudo, os animais sob suplementação com milho apresentaram maior EFIM $(P<0,10)$ em comparação aos animais sob suplementação com polpa cítrica (137,6 e 106,1 g PB microbiana/kg de NDT, respectivamente) (Tabela 5).

A relação entre PB digerida no intestino (PDI) e consumo de NDT não foi afetada pelos diferentes tratamentos $(\mathrm{P}>0,10)$, apresentando valor médio de $143,7 \mathrm{~g} / \mathrm{kg}$. De forma similar, não foram observadas alterações sobre a composição dos microrganismos ruminais ( $\mathrm{P}>0,10)$, observando estimativas médias de 6,92\% de nitrogênio, com base na MS, e 0,203 para a relação $\mathrm{N}_{\mathrm{RNA}}$ : $\mathrm{N}_{\text {TOTAL }}$ (Tabela 5).

Não foram observados efeitos $(\mathrm{P}>0,10)$ sobre o deslocamento ruminal de sólidos, observando-se estimativa média para o parâmetro taxa tempo-dependente $(\gamma)$ de $0,0333 \mathrm{~h}^{-1}$.

Os efeitos mais proeminentes causados pela suplementação residiram sobre a depressão no consumo voluntário de forragem (Tabela 3). A presença de efeito substitutivo sobre o consumo de forragem não é desejada, uma vez que o objetivo principal da suplementação em pastejo reside sobre a otimização do uso dos recursos forrageiros, promovendo ao mínimo sua substituição (Detmann et al., 2005b). Efeitos negativos sobre o consumo de pasto com o fornecimento de suplementos proteico-energéticos sob condições de forragem de alta qualidade foram relatados por outros autores em condições tropicais (Detmann et al., 2001; 2005b; Porto et al., 2008).

De forma geral, o efeito substitutivo obtido com a suplementação é diretamente proporcional à qualidade da forragem (Minson, 1990). Contudo, seria desejável, havendo substituição, que esta assumisse valores inferiores a $1,0 \mathrm{~g} / \mathrm{g}$, observando-se redução do consumo de pasto, mas ampliação do consumo total.

O efeito substitutivo observado neste estudo deixa claro que não se promoveu otimização no uso do pasto pelos animais, uma vez que este foi substituído cerca de duas vezes pelo suplemento. Por outro lado, a cada unidade de massa de suplemento fornecida, aproximadamente a mesma quantidade de FDN oriunda do pasto deixou de ser consumida (Tabela 4). Este segundo efeito substitutivo é particularmente deletério em regiões tropicais, dada a importância da FDN como fornecedora de energia de baixo custo para a produção bovina sob pastejo (Detmann et al., 2008).

Sob condições de predominância de entraves físicos ao consumo, efeitos deletérios sobre a taxa de degradação da FDN reduziriam a velocidade de retirada dos compostos fibrosos insolúveis do ambiente ruminal, os quais estão associados à repleção física (Paulino et al., 2008).

A FDNi constitui um dos principais elementos associados aos mecanismos de regulação física do consumo de forragens tropicais (Detmann et al., 2003; Sampaio et al., 2009), uma vez que, proporcionalmente, apresenta maior efeito de repleção por ser retirada do ambiente ruminal 
somente por passagem (Lazzarini et al., 2009; Sampaio et al., 2009). A velocidade de retirada da FDNi do ambiente ruminal está teoricamente associada com a velocidade de degradação da FDN potencialmente degradável (FDNpd) (Detmann et al., 2008). Assim, em termos teóricos, caso a suplementação afetasse a degradação ruminal da FDNpd, observar-se-ia redução na taxa de deslocamento ruminal da fibra, o que não foi observado $(\mathrm{P}>0,10)$.

Isto parece indicar que não ocorreram restrições físicas causadas pela suplementação sobre a dinâmica de trânsito da FDNi, o que deveria suportar consumos similares entre animais sob suplementação e sem suplementação. Contudo, observou-se queda no consumo de FDNi com o fornecimento de suplementos (Tabela 4). Isto indica que a hipótese de inibição de consumo pela suplementação através de incrementos nos fatores associados aos mecanismos físicos de regulação é inconsistente para a presente situação.

O consumo médio de FDN em animais sob suplementação encontra-se próximo ao sugerido por modelos estáticos como limitante sob a predominância de mecanismos físicos. Contudo, a adoção de um ponto de transição para o predomínio de mecanismos regulatórios, com consumo de FDN estático, constitui simplificação matemática conveniente, pois o efeito de repleção ruminal diminui gradualmente com a ampliação da digestibilidade. Desta forma, a transição entre a predominância de mecanismos regulatórios (físico e metabólico) é mais bem representada por um intervalo em que se observaria forte interação entre estes (Detmann et al., 2003).

Mesmo com consumo de FDN próximo ao que seria esperado com a predominância de mecanismos físicos de regulação do consumo, aspectos metabólicos podem ser mais proeminentes quando pasto de alta qualidade é disponibilizado aos animais (Detmann et al., 2005a). Por outro lado, mecanismos integrados do consumo têm sido propostos sob a ótica multifatorial associada à minimização do desconforto animal. Sob este ponto de vista, o animal regularia seu consumo de forma a equilibrar todos os fatores físicos e metabólicos para se manter fisiologicamente em conforto (Forbes, 2007).

Entre os fatores associados ao desconforto e, conseqüentemente, ao controle do consumo, destaca-se a relação proteína metabolizável:energia metabolizável (PM:EM) (Illius \& Jessop, 1996; Detmann et al., 2010). Neste sentido, existiria intervalo ideal para esta razão, fora do qual o consumo seria restringido pelo catabolismo proteico (alta relação PM:EM) ou pela necessidade de eliminação de calor (baixa relação PM:EM) (Illius \& Jessop, 1996), o que, possivelmente resultaria em desconforto ao animal.
Assumindo-se que a massa de PDI e o consumo de NDT sejam indicadores da provisão de proteína metabolizável e energia metabolizável ao animal, respectivamente, então a razão PDI:NDT pode ser assumida como indicador da razão PM:EM.

A relação PDI:NDT neste estudo não diferiu entre tratamentos, apresentando valor médio de 143,7 g PDI/kg NDT (Tabela 5). Isto pode indicar que a depressão no consumo de forragem pode ter acontecido para manutenção da relação PM:EM em patamares adequados ao conforto animal, evitando excesso relativo de energia circulante. Ao que tudo indica, a substituição de grande massa de forragem de menor digestibilidade, por pequena massa de suplemento de maior digestibilidade manteve constante o teor (Tabela 4) e o consumo energético (Tabela 3).

Esta hipótese parece plausível sob tais condições, pois os efeitos substitutivos são maiores com forragens de alta qualidade em comparação a forragens de baixa qualidade (Minson, 1990). Forragens de baixa qualidade possuem menor digestibilidade e, conseqüentemente, menor teor energético. Assim, com a introdução de suplementos de alta digestibilidade, a redução na massa de forragem ingerida para se manter ou colocar a relação PM:EM na faixa ideal seria menor em comparação a situações nas quais a forragem apresenta alta qualidade, como observado neste estudo.

Pastos tropicais durante o período das águas apresentam relação energia/proteína acima daquelas demandadas pelos animais, implicando excesso relativo de energia em relação à proteína (Detmann et al., 2010). Assim, nestas circunstâncias, a suplementação proteico-energética, como utilizada neste estudo, forçaria ainda mais o desequilíbrio na razão energia/proteína, reduzindo o consumo de pasto por intermédio de mecanismos metabólicos, como discutido anteriormente.

Em vários experimentos nos quais foram utilizados suplementos com altos níveis de PB (normalmente superiores a 50-60\%), foram observados consumos similares de forragem entre animais sob suplementação e sem suplementação (Zervoudakis et al., 2008; Costa, 2009; Porto, 2009), ou seja, ausência de efeito substitutivo.

Assim, a utilização de altos níveis de PB podem exigir menor redução no consumo de energia a partir da forragem para manutenção da relação PM:EM dentro de uma faixa confortável ao animal e compatível com as demandas metabólicas. Assim, isto parece indicar que a suplementação com altos níveis proteicos pode ser mais adequada para se maximizar o uso de forragem em animais manejados em pastos de alta qualidade em comparação à suplementação proteico-energética, com níveis moderados de PB. 
Um dos diferenciais positivos da suplementação durante o período das águas seria baseado no aumento da concentração de NAR; contudo, não foram observadas diferenças entre animais sob suplementação e sem suplementação (Tabela 5).

Recentes pressupostos teóricos definidos em condições tropicais têm estabelecido o rúmen como dreno de ureia, o que reduziria a disponibilidade de compostos nitrogenados para a síntese de tecidos corporais (Costa, 2009; Detmann et al., 2010). A utilização de aminoácidos para síntese de ureia poderia estar associada à baixa retenção de nitrogênio em ruminantes alimentados com forragens (Parker et al., 1995).

O dreno de ureia pelo rúmen durante o período das águas seria superior ao observado durante o período da seca, pois a transferência de ureia para o ambiente ruminal é positivamente regulada pelo consumo de MO degradada no rúmen (Kennedy et al., 1981). O consumo de MO degradada no rúmen pode ser até $80 \%$ superior no período das águas em comparação ao período da seca (Detmann et al., 2010).

A concentração de NAR constitui mecanismo de regulação negativa da transferência de ureia do pool sanguíneo para o rúmen (Kennedy \& Milligan, 1978; Kennedy et al., 1981). Assim, ao incrementar a concentração de NAR, o uso de suplementos reduziria o deslocamento de substratos nitrogenados para a síntese de ureia hepática, ampliando a disponibilidade desses substratos, principalmente aminoácidos, para a síntese de tecido corporal (Costa, 2009).

A idéia de dreno de ureia é reiterada pelos coeficientes de digestibilidade ruminal da PB, que foram negativos na ausência de suplementação (Tabela 4), indicando balanço negativo de compostos nitrogenados no rúmen, dado, possivelmente, pelo direcionamento de compostos nitrogenados absorvidos no intestino para reciclagem ao invés de deposição de proteína corporal (Detmann et al., 2010).

A ampliação da concentração de NAR está associada à ampliação na retenção corporal de nitrogênio em animais manejados a pasto durante o período das águas (Detmann et al., 2010).

A similaridade entre animais sob suplementação e sem suplementação quanto ao consumo de MO (Tabela 4) e ao coeficiente de digestibilidade ruminal da MO (Tabela 5) permite inferir que similaridade também seria observada quanto ao consumo de MO degradada no rúmen. Logo, diferenças quanto ao dreno de ureia em função da regulação via MO degradada no rúmen não seriam esperadas.

Desta forma, a variação na concentração de NAR consistiria no principal mecanismo de regulação da transferência de ureia. Segundo os pressupostos anteriormente apresentados, não havendo diferenças entre animais sob suplementação e sem suplementação quanto à concentração de NAR (Tabela 5), e sendo estável o consumo de MO degradada no rúmen, a massa de compostos nitrogenados destinada à síntese de tecidos não seria ampliada, o que concorda plenamente com as estimativas de balanço de compostos nitrogenados obtidas neste estudo, que não diferiram entre animais sob suplementação e sem suplementação (Tabela 5).

Por outro lado, a ausência de efeitos da suplementação sobre o fluxo de nitrogênio microbiano no abomaso (Tabela 5) não permitiu aos animais sob suplementação ampliar o suprimento de proteína metabolizável a partir da proteína microbiana. Isto parece ser reflexo do efeito substitutivo, uma vez que o consumo total de substratos para o crescimento microbiano manteve-se estável (Tabela 3).

Mesmo que a suplementação tenha elevado as estimativas do coeficiente de digestibilidade ruminal da $P B$, estes se mantiveram em patamares ainda baixos (Tabela 4), o que indica que pouco ou nenhum efeito tenha sido observado sobre a transferência de ureia para o rúmen. Segundo Detmann et al. (2010), a maximização do coeficiente de digestibilidade ruminal da PB é conseguida em bovinos manejados em pastos durante o período das águas com níveis de NAR próximos a 13 mg/dL, estimativa superior a todos os tratamentos avaliados neste estudo (Tabela 5).

A ausência de incremento na concentração de NAR com a suplementação parece residir sobre o fato de o efeito substitutivo sobre o consumo de PB ter sido próximo a $1,0 \mathrm{~g} / \mathrm{g}$, ou seja, houve manutenção do consumo total de PB com a suplementação (Tabela 3).

Por outro lado, embora as fontes proteicas suplementares sejam de alta degradabilidade, o fornecimento conjunto de CNF pode ter permitido a proliferação de espécies de microrganismos com alta taxa de crescimento e, conseqüentemente, com alta taxa de assimilação de nitrogênio em comparação aos microrganismos fibrolíticos. O acúmulo ruminal de amônia é influenciado pela entrada (consumo de nitrogênio e reciclagem), pela passagem ao trato posterior e pela assimilação microbiana. Assim, a alta degradabilidade da PB suplementar parece ter sido contrabalanceada pela maior assimilação microbiana, evitando ampliação da concentração de NAR.

Isso confirma que a suplementação com altos níveis de proteína poderia ser mais vantajosa para otimização da utilização de forragem de alta qualidade em comparação à suplementação proteico-energética, como a utilizada neste estudo.

De forma geral, as alterações das fontes de carboidratos ou de compostos nitrogenados nos suplementos causaram 
impactos de pouca magnitude sobre as variáveis avaliadas neste estudo.

O incremento nos coeficientes de digestibilidade total do EE com a substituição do milho por polpa e dos CNF com a substituição do farelo de soja por ureia refletem a maior concentração destes componentes nos suplementos (Tabela 2), o que incrementa sua participação na dieta total, reduzindo a participação relativa da fração metabólica fecal (Van Soest, 1994).

Uma das diferenças mais proeminentes entre fontes e carboidratos foi verificada por intermédio da redução na eficiência de crescimento microbiano quando o milho foi substituído por polpa cítrica (Tabela 5).

A pectina, principal componente da polpa cítrica, embora sendo CNF, apresenta padrão de fermentação similar ao de carboidratos fibrosos, mas sendo, contudo, mais rápido (Van Soest, 1994). Desta forma, estas características intrínsecas à pectina podem ter causado maior competição por amônia no ambiente ruminal, o que é suportado pela menor concentração de NAR em comparação ao milho, embora sem efeitos significativos $(\mathrm{P}>0,10)$ (Tabela 5). Assim, a maior competição entre os microrganismos responsáveis pela degradação da pectina e aqueles responsáveis pela degradação dos carboidratos fibrosos da forragem conduziu a menor produção microbiana, embora sem efeito significativo $(P>0,10)$ em comparação ao milho. Sendo a produção microbiana numerador da eficiência, justifica-se, ao menos em parte, a menor eficiência com a suplementação com polpa cítrica.

Por outro lado, a maior eficiência de produção microbiana com o uso de milho em comparação à polpa cítrica pode estar associada ao fato de haver maior digestão total dos CNF com o uso de polpa (Tabela 5). Como os carboidratos são essencialmente a fonte energética majoritária para o crescimento microbiano, a maior digestão dos CNF com o uso de polpa amplia o denominador para o cálculo da eficiência.

A menor digestão total dos CNF com o uso do milho pode estar associada à presença de amido com estrutura resistente à degradação ruminal. Parte deste amido pode ser digerida no intestino grosso (Eerlingen \& Delcour, 1995). Contudo, a digestão de amido no intestino grosso amplia a atividade microbiana neste sítio e incorre em elevação na excreção de debris microbianos, ampliando a excreção de nitrogênio metabólico fecal (Ørskov, 1988). Esta hipótese parece ser plausível no presente estudo, pois se verificou maior excreção de nitrogênio fecal com a suplementação baseada em milho em comparação à polpa cítrica (Tabela 5).

\section{Conclusões}

A suplementação proteico-energética para bovinos mantidos em pastos tropicais durante o período das águas não apresenta benefícios nutricionais, o que reflete o alto coeficiente de substituição da forragem pelo suplemento. Nessas condições, não são observados impactos nutricionais relevantes da substituição de fontes energéticas ricas em amido por fibra solúvel, ou fontes de compostos nitrogenados proteicos por não-proteicos.

\section{Referências}

CASALI, A.O.; DETMANN, E.; VALADARES FILHO, S.C. et al. Influência do tempo de incubação e do tamanho de partículas sobre os teores de compostos indigestíveis em alimentos e fezes bovinas obtidos por procedimentos in situ. Revista Brasileira de Zootecnia, v.37, p.335-342, 2008.

CECAVA, J.M.; MERCHEN, N.R.; GAY, L.C. et al. Composition of ruminal bacteria harvested from steers as influenced by dietary energy level, feeding frequency, and isolation techniques. Journal of Dairy Science, v.73, p.2480-2488, 1990.

CHANEY, A.L.; MARBACH, E.P. Modified reagents for determination of urea and ammonia. Clinical Chemistry, v.8, p.130-132, 1962.

CHIZZOTTI, M.L.; VALADARES FILHO, S.C.; VALADARES, R.F.D. et al. Consumo, digestibilidade e excreção de ureia e derivados de purinas em novilhas de diferentes pesos. Revista Brasileira de Zootecnia, v.35, p.1813-1821, 2006.

COSTA, V.A.C. Desempenho nutricional de bovinos em pastejo durante o período das águas com suplementação proteica ou proteico-energética. 2009. 90f. Tese (Doutorado em Zootecnia) - Universidade Federal de Viçosa, Viçosa, MG.

COSTA, V.A.C.; DETMANN, E.; VALADARES FILHO, S.C. et al. Degradação in vitro da fibra em detergente neutro de forragem tropical de alta qualidade em função da suplementação com proteína e/ou carboidratos. Revista Brasileira de Zootecnia, v.38, p.1803-1811, 2009.

DETMANN, E.; VALADARES FILHO, S.C. On the estimation of non-fibrous carbohydrates in feeds and diets. Arquivo Brasileiro de Medicina Veterinária e Zootecnia, v.62, p.980-984, 2010.

DETMANN, E.; PAULINO, M.F.; ZERVOUDAKIS, J.T. et al. Suplementação de novilhos mestiços durante a época das águas: parâmetros ingestivos e digestivos. Revista Brasileira de Zootecnia, v.30, p.1340-1349, 2001.

DETMANN, E.; QUEIROZ, A.C.; CECON, P.R. et al. Consumo de fibra em detergente neutro por bovinos em confinamento. Revista Brasileira de Zootecnia, v.32, p.1763-1777, 2003. DETMANN, E.; PAULINO, M.F.; VALADARES FILHO, S.C. et al. Níveis de proteína em suplementos para terminação de bovinos em pastejo durante período de transição seca/águas: digestibilidade aparente e parâmetros do metabolismo ruminal e dos compostos nitrogenados. Revista Brasileira de Zootecnia, v.34, p.1380-1391, 2005a.

DETMANN, E.; PAULINO, M.F.; CECON, P.R. et al. Níveis de proteína em suplementos para terminação de bovinos em pastejo durante o período de transição seca/águas: consumo voluntário e trânsito de partículas. Revista Brasileira de Zootecnia, v.34, p.1371-1379, 2005b.

DETMANN, E.; PAULINO, M.F.; VALADARES FILHO, S.C. Avaliação nutricional de alimentos ou de dietas? Uma abordagem conceitual. In: SIMPÓSIO DE PRODUÇÃO DE GADO DE CORTE, 6., 2008, Viçosa, MG. Anais... Viçosa, MG: DZO-UFV, 2008. p.21-52. 
DETMANN, E.; PAULINO, M.F.; VALADARES FILHO, S.C. Otimização do uso de recursos forrageiros basais. In: SIMPÓSIO DE PRODUÇÃO DE GADO DE CORTE, 7, 2010, Viçosa, MG. Anais... Viçosa, MG: DZO-UFV, 2010. p.191-240.

ELLIS, W.C.; MATIS, J.H.; HILL, T.M. et al. Methodology for estimating digestion and passage kinetics of forages. In: FAHEY J.R., G.C. (Ed.) Forage quality, evaluation and utilization. Madison: American Society of Agronomy, 1994. p.450-493.

EERLINGEN, R.C.; DELCOUR, J.A. Formation, analysis, structure and properties of type III enzyme resistant starch. Journal of Cereal Science, v.22, p.129-138, 1995.

FIGUEIREDO, D.M.; PAULINO, M.F.; DETMANN, E. et al. Fontes de proteína em suplementos múltiplos para bovinos em pastejo no período das águas. Revista Brasileira de Zootecnia, v.37, p.2222-2232, 2008.

FORBES, J.M. A personal view of how ruminant animals control their intake and choice of food: minimal total discomfort. Nutrition Research Review, v.20, p.132-146, 2007.

ILLIUS, A.W.; JESSOP, N.S. Metabolic constraints on voluntary intake in ruminants. Journal of Animal Science, v.74, p.3052-3062, 1996.

KENNEDY, M.P.; MILLIGAN, L.P. The effects of dietary sucrose and the concentrations of plasma urea and rumen ammonia on the degradation of urea in the gastrointestinal tract of cattle. British Journal of Nutrition, v.43, p.125-140, 1978.

KENNEDY, P.M.; CLARKE, R.T.J.; MILLIGAN, L.P. Influences of dietary sucrose and urea on transfer of endogenous urea to the rumen of sheep and numbers of epithelial bacteria. British Journal of Nutrition, v.46, p.533-541, 1981

LAZZARINI, I.; DETMANN, E.; SAMPAIO, C.B. et al. Dinâmicas de trânsito e degradação da fibra em detergente neutro em bovinos alimentados com forragem tropical de baixa qualidade e compostos nitrogenados. Arquivo Brasileiro de Medicina Veterinária e Zootecnia, v.61, p.635-647, 2009.

LICITRA, G.; HERNANDES, T.M.; Van SOEST, P.J. Standardization of procedures for nitrogen fractionation of ruminants feeds. Animal Feed Science and Technology, v.57, p.347-358, 1996.

MERTENS, D.R. Gravimetric determination of amylase-treated neutral detergent fiber in feeds with refluxing in beakers or crucibles: collaborative study. Journal of AOAC International, v.85, p.1217-1240, 2002

MINSON, D.J. Forage in ruminant nutrition. San Diego: Academic Press, 1990. 483p.

ØRSKOV, E.R. Nutrición proteica de los rumiantes. Zaragoza: Acribia, 1988. 178p.

PARKER, D.S.; LOMAX, M.A.; SEAL, C.J. et al. Metabolic implications of ammonia production in the ruminant. Proceedings of Nutrition Society, v.54, p.549-563, 1995.

PAULINO, M.F.; MORAES, E.H.B.K.; ZERVOUDAKIS, J.T. et al. Terminação de novilhos mestiços leiteiros sob pastejo, no período das águas, recebendo suplementação com soja. Revista Brasileira de Zootecnia, v.35, p.154-158, 2006.

PAULINO, M.F.; DETMANN, E.; VALENTE, E.E.L. et al. Nutrição de bovinos em pastejo. In: SIMPÓSIO SOBRE MANEJO ESTRATÉGICO DA PASTAGEM, 4., 2008, Viçosa, MG. Anais... Viçosa, MG: DZO-UFV, 2008. p.131-169.

POPPI, D.P.; McLENNAN, S.R. Protein and energy utilization by ruminants at pasture. Journal of Animal Science, v.73, p.278-290, 1995.

PORTO, M.O. Suplementos múltiplos para bovinos de corte nas fases de cria, recria e terminação em pastagens de Brachiaria decumbens. 2009. 140f. Tese (Doutorado em Zootecnia) - Universidade Federal de Viçosa, Viçosa, MG.

PORTO, M.O.; PAULINO, M.F.; VALADARES FILHO, S.C. et al. Formas de utilização do milho em suplementos para novilhos na fase de terminação em pastagem no período das águas: desempenho e parâmetros nutricionais. Revista Brasileira de Zootecnia, v.37, p.2251-2260, 2008.

REGAZZI, A.J. Teste para verificar a igualdade de parâmetros e identidade de modelos de regressão não-linear. Ceres, v.50, p.9-26, 2003.

SAMPAIO, C.B.; DETMANN, E.; LAZZARINI, I. et al. Rumen dynamics of neutral detergent fiber in cattle fed low-quality tropical forage and supplemented with nitrogenous compounds. Revista Brasileira de Zootecnia, v.38, p.560-569, 2009.

SILVA, D.J.; QUEIROZ, A.C. Análise de alimentos: métodos químicos e biológicos. 3.ed. Viçosa, MG: Editora UFV, 2002. 235p.

TITGEMEYER, E.C.; ARMENDARIZ, C.K.; BINDEL, D.J. et al. Evaluation of titanium dioxide as a digestibility marker for cattle. Journal of Animal Science, v.79, p.1059-1063, 2001.

UDÉN, P.; COLUCCI, P.E.; Van SOEST, P.J. Investigation of chromium, cerium and cobalt as markers in digesta. Rate of passage studies. Journal of the Science Food and Agriculture, v.31, p.625-632, 1980

USHIDA, K.; LASSALAS, B.; JOUANY, J.P. Determination of assay parameters for RNA analysis in bacterial and duodenal samples by spectrophotometry. Influence of treatment and preservation. Reproduction Nutrition Development, v.25, p.1037-1046. 1985.

VALADARES FILHO, S.C.; PAULINO, P.V.R.; MAGALHÃES, K.A. Exigências nutricionais de zebuínos e tabelas de composição de alimentos BR-Corte. Viçosa, MG: DZO-UFV, 2006. 142p.

Van SOEST, P.J. Nutritional ecology of the ruminant. 2.ed. Ithaca: Cornell University Press, 1994. 476p.

ZERVOUDAKIS, J.T.; PAULINO, M.F.; CABRAL, L.S. et al. Suplementos múltiplos de auto controle de consumo na recria de novilhos no período das águas. Ciência e Agrotecnologia, v.32, p.1968-1973, 2008. 